\title{
Columnar Organization of Dendrites and Axons of Single and Synaptically Coupled Excitatory Spiny Neurons in Layer 4 of the Rat Barrel Cortex
}

\author{
Joachim Lübke,, ${ }^{1}$ Veronica Egger, ${ }^{2}$ Bert Sakmann,,2 and Dirk Feldmeyer ${ }^{2}$ \\ ${ }^{1}$ Anatomisches Institut I, Albert-Ludwigs-Universität Freiburg, D-79104 Freiburg, Germany, and 2Max-Planck-Institut für \\ Medizinische Forschung, Abteilung Zellphysiologie, D-69120 Heidelberg, Germany
}

Cortical columns are the functional units of the neocortex that are particularly prominent in the "barrel" field of the somatosensory cortex. Here we describe the morphology of two classes of synaptically coupled excitatory neurons in layer 4 of the barrel cortex, spiny stellate, and star pyramidal cells, respectively. Within a single barrel, their somata tend to be organized in clusters. The dendritic arbors are largely confined to layer 4, except for the distal part of the apical dendrite of star pyramidal neurons that extends into layer $2 / 3$. In contrast, the axon of both types of neurons spans the cortex from layer 1 to layer 6 . The most prominent axonal projections are those to layers 4 and $2 / 3$ where they are largely restricted to a single cortical column. In layers 5 and 6 , a small fraction of axon collaterals projects also across cortical columns. Consistent with the dense axonal projection to layers 4 and $2 / 3$, the total number and density of boutons per unit axonal length was also highest there. Electron microscopy combined with GABA postimmunogold labeling revealed that most $(>90 \%)$ of the synaptic contacts were established on dendritic spines and shafts of excitatory neurons in layers 4 and 2/3.

The largely columnar organization of dendrites and axons of both cell types, combined with the preferential and dense projections within cortical layers 4 and 2/3, suggests that spiny stellate and star pyramidal neurons of layer 4 serve to amplify thalamic input and relay excitation vertically within a single cortical column.

Key words: barrel cortex; layer 4; spiny stellate cell; star pyramidal neuron; cortical column; axonal projection; paired recordings; intracellular labeling
Sensory cortices display a distinctive organization into functional modules of neuronal ensembles, the so-called cortical columns that process signals from the periphery (Mountcastle, 1957; Mountcastle and Powell, 1959; Hubel and Wiesel, 1962; for review, see Mountcastle, 1997; Rockland, 1998). One striking example of such a modular organization is the "barrel" field in the somatosensory cortex of rodents. In layer 4 of the barrel cortex, each whisker hair on the animal's muzzle is topographically represented in a one-toone relationship (Woolsey and van der Loos, 1970; Welker, 1976; for review, see Juliano and Jacobs, 1995).

In sensory cortices, layer 4 is the main input region for afferent fibers originating in the respective thalamic relay nuclei (Hubel and Wiesel, 1962; McGuire et al., 1984; Chiaia et al., 1991a,b; for review, see Sherman and Guillery, 1996). Although a small fraction $(\sim 20 \%)$ of these thalamic afferents terminate on aspinous, presumably GABAergic interneurons (White and Rock, 1981; White et al., 1984; Benshalom and White, 1986), their main target cells are excitatory spiny neurons in layer 4 . Most of these neurons resemble spiny stellate cells, whereas a smaller fraction has been described as star pyramidal cells (Lund, 1984; Ahmed et al., 1994; Hirsch, 1995). Thus, these neurons are the first elements involved in intracortical signal processing (Mountcastle and Powell, 1959; Hubel and Wiesel, 1962; LeVay, 1973; Martin and Whitteridge, 1984; McGuire et al., 1984; Douglas and Martin, 1991; ArmstrongJames et al., 1992; for review, see McCormick, 1992).

An understanding of the function of spiny neurons in layer 4 in the microcircuitry of a cortical column requires detailed knowledge about their anatomical organization, in particular their axonal

\footnotetext{
Received Nov. 24, 1999; revised April 28, 2000; accepted April 29, 2000.

This work was supported by the Deutsche Forschungsgemeinschaft (SFB 505/C6) and the Max-Planck-Society. We thank Dr. Imre Vida and Arnd Roth for critically reading an earlier version of this manuscript. We are also grateful to B. Joch, S. Nestel, M. Winter, and I. Dehof for excellent technical assistance.

Correspondence should be addressed to Dr. Joachim Lübke, Anatomisches Institu der Albert-Ludwigs-Universität Freiburg, Albertstraße 17, D-79104 Freiburg, Germany. E-mail: luebkejo@uni-freiburg.de.

Copyright (C) 2000 Society for Neuroscience $0270-6474 / 00 / 205300-12 \$ 15.00 / 0$
}

projections and their postsynaptic target cells. Earlier Golgi studies described the dendritic morphology of spiny neurons in rodent barrel cortex (Pasternak and Woolsey, 1975; Woolsey et al., 1975; Steffen, 1976; Steffen and van der Loos, 1980; Harris and Woolsey, 1981; Simons and Woolsey, 1984; for review, see Juliano and Jacobs, 1995) but lacked information about the axonal projections at the single-cell level and the target cells of these neurons. However, small extracellular biocytin deposits revealed that most of the projections are to supragranular layers, and relatively few direct connections exist between hollows of neighboring barrels (Kim and Ebner, 1999).

Here we have used dual whole-cell recordings from pairs of neurons combined with reconstruction of the biocytin-filled neurons to quantitatively describe the dendritic arborization and in particular the axonal projections and the postsynaptic target structures of synaptically coupled spiny neurons in layer 4 of rat barrel cortex. We show that the dendritic arbor is largely confined to a single barrel in layer 4 and that the axon projects vertically throughout all cortical layers but remains predominantly within the same cortical column. In conjunction with the functional properties of these connections (Feldmeyer et al., 1999b), the largely columnar organization of the axons suggests that as an ensemble, excitatory spiny neurons in layer 4 serve to amplify thalamic inputs and relay excitation to superficial laminae within a cortical column. Therefore, spiny layer 4 neurons act as the principal gate for the signal flow within a cortical column.

\section{MATERIALS AND METHODS}

Preparation of acute brain slices. All experiments were performed in accordance with the animal welfare guidelines of the Max-Planck Society and the University of Freiburg. Wistar rats (12-22 d old) were anesthetized with halothane and decapitated, and slices through the somatosensory cortex were cut in cold extracellular solution using a vibrating microslicer (DTK-1000, Dosaka Co. Ltd., Kyoto, Japan) and prepared according to methods described elsewhere (Agmon and Connors, 1991; Feldmeyer et al., 1999b). Slices ( $350-400 \mu \mathrm{m}$ thick) were collected, incubated at $35^{\circ} \mathrm{C}$ in extracellular solution for 30-60 min, and subsequently maintained at room temperature $\left(20-23^{\circ} \mathrm{C}\right)$ before electrical recordings were made. 
A
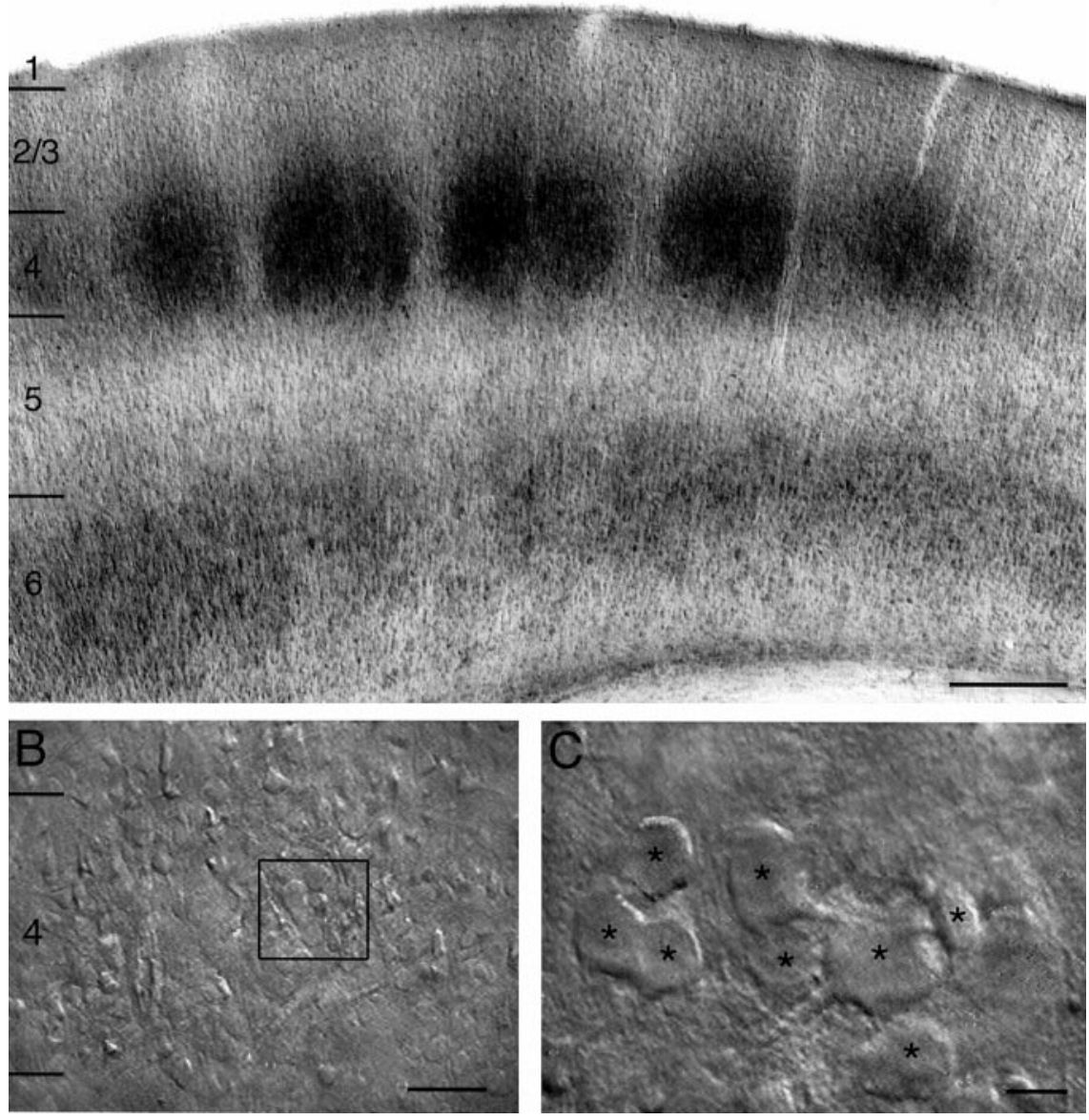

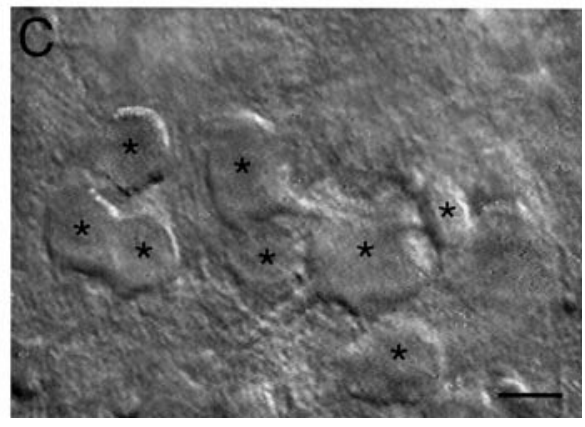

Figure 1. A, Low magnification of a semicoronal section through the barrel field (as used for acute slices) stained for cytochrome oxidase showing the regular distribution of barrels in layer 4 of the somatosensory cortex. Scale bar, $500 \mu \mathrm{m}$. $B$, Low magnification IR-DIC contrast image of layer 4 of the barrel cortex. The box outlined in black indicates a cluster of spiny layer 4 neurons that is shown enlarged in $C$. Scale bar, $200 \mu \mathrm{m}$. $C$, Higher magnification of a single cluster of spiny layer 4 neurons. All neurons in the plane of focus are marked by black asterisks. Scale bar, $10 \mu \mathrm{m}$.
Solutions. Slices were continuously superfused with extracellular solution containing (in $\mathrm{mM}$ ): $125 \mathrm{NaCl}, 2.5 \mathrm{KCl}, 25$ glucose, $25 \mathrm{NaHCO}_{3}, 1.25$ $\mathrm{NaH}_{2} \mathrm{PO}_{4}, 2 \mathrm{CaCl}_{2}$ and $1 \mathrm{MgCl}_{2}$ bubbled with $95 \% \mathrm{O}_{2}$ and $5 \% \mathrm{CO}_{2}$. The intracellular pipette solution contained (in mM): $105 \mathrm{~K}$-gluconate, $30 \mathrm{KCl}$, 10 HEPES, 10 phosphocreatine, 4 ATP-Mg, 0.3 GTP (adjusted to $\mathrm{pH} 7.3$ with $\mathrm{KOH}$ ). The osmolarity of this solution was $300 \mathrm{mOsm}$. For subsequent morphological analysis, $2-5 \mathrm{mg} / \mathrm{ml}$ biocytin (Sigma, München, Germany) was routinely added to the internal solution, and neurons were filled during $1-3 \mathrm{hr}$ of recording.

Identification of synaptically connected neurons in layer 4 of the barrel cortex. Slices of rat somatosensory cortex were placed in the recording chamber under an upright microscope (Axioskop Carl Zeiss Göttingen, Germany) fitted with $2.5 \times$ plan $/ 0.075 \mathrm{NA}$ and $40 \times-\mathrm{W} / 0.80$ objectives) with the pial surface pointing to the front and the hippocampus to the right. The barrel field was visualized at low magnification under bright-field illumination and can be identified in layer 4 as evenly spaced dark structures. Barrel structures are present in five to six slices but a continuous band of barrels is visible only in two to three slices just above the hippocampus, fimbria-fornix, and lateral ventricle. Individual layer 4 neurons were identified at $40 \times$ magnification using infrared-differential interference contrast (IR-DIC) microscopy as previously described. The somata of layer 4 neurons in the barrel field tended to be organized in clusters in the dark edges of a barrel (see Fig. $1 B, C$ ) when compared with the light centers.

Electrophysiological recordings. Whole-cell voltage recordings from presynaptic and postsynaptic spiny layer 4 neurons were made as described elsewhere (Feldmeyer et al., 1999b). In brief, a postsynaptic cell was recorded from with one pipette, and subsequently synaptic connections to this cell were searched with a second pipette in the loose-patch configuration. When EPSPs in response to the loose-patch stimulation were detected in the postsynaptic neuron, the presynaptic cell was repatched with a new pipette filled with biocytin-containing intracellular solution using the whole-cell (voltage recording) mode. Potentials were amplified using an EPC9-2 (for dual whole-cell recording; HEKA Elektronik Lambrecht). Recordings were filtered at $2-5 \mathrm{kHz}$, digitized at $5-10 \mathrm{kHz}$ using an ITC-16 interface (Instrutech, Great Neck, NY), and stored on the hard disk of a Macintosh or a PC.

Histological procedures. After recording and loading with biocytin, brain slices were fixed in $100 \mathrm{~mm}$ phosphate-buffered (PB) solution, pH 7.4, containing $1 \%$ paraformaldehyde and $2.5 \%$ glutaraldehyde at $4{ }^{\circ} \mathrm{C}$ for at least $24 \mathrm{hr}$. Endogenous peroxidase was blocked by incubation of the slices in $1 \% \mathrm{H}_{2} \mathrm{O}_{2}$ for $15-20 \mathrm{~min}$. After several rinses in $\mathrm{PB}$ solution they were then transferred to a $1 \%$ avidin-biotinylated horseradish peroxidase complex containing $0.1 \%$ Triton X-100 (ABC-Elite Camon, Wiesbaden, Germany) and left overnight at $4^{\circ} \mathrm{C}$ while shaking slightly. The next day, slices were reacted using 3,3-diaminobenzidine (DAB; Sigma) and $0.01 \% \mathrm{H}_{2} \mathrm{O}_{2}$ until dendrites and axonal arbors were clearly visible (after approximately 2-5 $\mathrm{min}$ ). Slices were mounted on glass slides, embedded in Moviol (Hoechst AG, Frankfurt AM, Germany), and coverslipped.

Individual selected spiny stellate $(n=2)$ and star pyramidal neurons $(n=1)$ were processed for electron microscopic analysis to identify the postsynaptic target structures of these neurons. After cryoprotection in $10 \%(20 \mathrm{~min})$ and $20 \%(30 \mathrm{~min})$ sucrose, sections were freeze-thawed in liquid nitrogen. After several rinses in PB solution, sections were incubated overnight in $\mathrm{ABC}$ solution and reacted as described above. To enhance staining contrast, slices were post-fixed in $0.5 \% \mathrm{OsO}_{4}(30-45 \mathrm{~min})$, then dehydrated and embedded in Durcupan (Fluka, Deisenhofen, Germany). Serial ultrathin sections through the entire axonal domain were cut with an ultramicrotome (Leitz-Ultracut, Hamburg, Germany), counterstained, and examined with a Philips CM 100 electron microscope (Philips, Eindhoven, The Netherlands).

GABA postembedding immunogold labeling. The immunogold staining procedure was performed as described by Somogyi and Hodgson (1985), using a commercially available antiserum against GABA (Sigma). The immunostaining was performed on droplets of Millipore-filtered solutions in humid Petri dishes. Immersion in $1 \%$ periodate $(10 \mathrm{~min})$ was followed by several washes in double-distilled water. Thereafter, the grids were transferred through 2 or $5 \%$ sodium metaperiodate $(10-30 \mathrm{~min})$ and rinsed several times in double-distilled water and three times in Trisbuffered saline (TBS), $\mathrm{pH}$ 7.4. After preincubation in $1 \%$ ovalbumin dissolved in TBS (30 min), the grids were incubated in rabbit anti-GABA antiserum (1:5000, in 1\% normal goat serum in TBS). After rinsing in TBS and $50 \mathrm{~mm}$ Tris buffer, $\mathrm{pH} 7.4$, containing $1 \%$ bovine serum and $0.5 \%$ Tween $20(10 \mathrm{~min})$, the grids were incubated in the secondary antibody (goat anti-rabbit IgG-coated colloidal gold, $10 \mathrm{~nm}$ ) for $2 \mathrm{hr}$ (diluted 1:10, in darkness). After rinsing in $2 \%$ glutaraldehyde $(10 \mathrm{~min})$, the grids were washed again in double-distilled water and stained with uranyl acetate and lead citrate. In control experiments without the primary antibody and sections processed for GABA postimmunogold labeling, almost no or only low background labeling was detected, whereas labeling of structures presumed to be GABAergic exceeded the mean gold particle density of the maximal background staining by at least four SDs.

Morphological reconstructions of biocytin-filled synaptically coupled neu- 

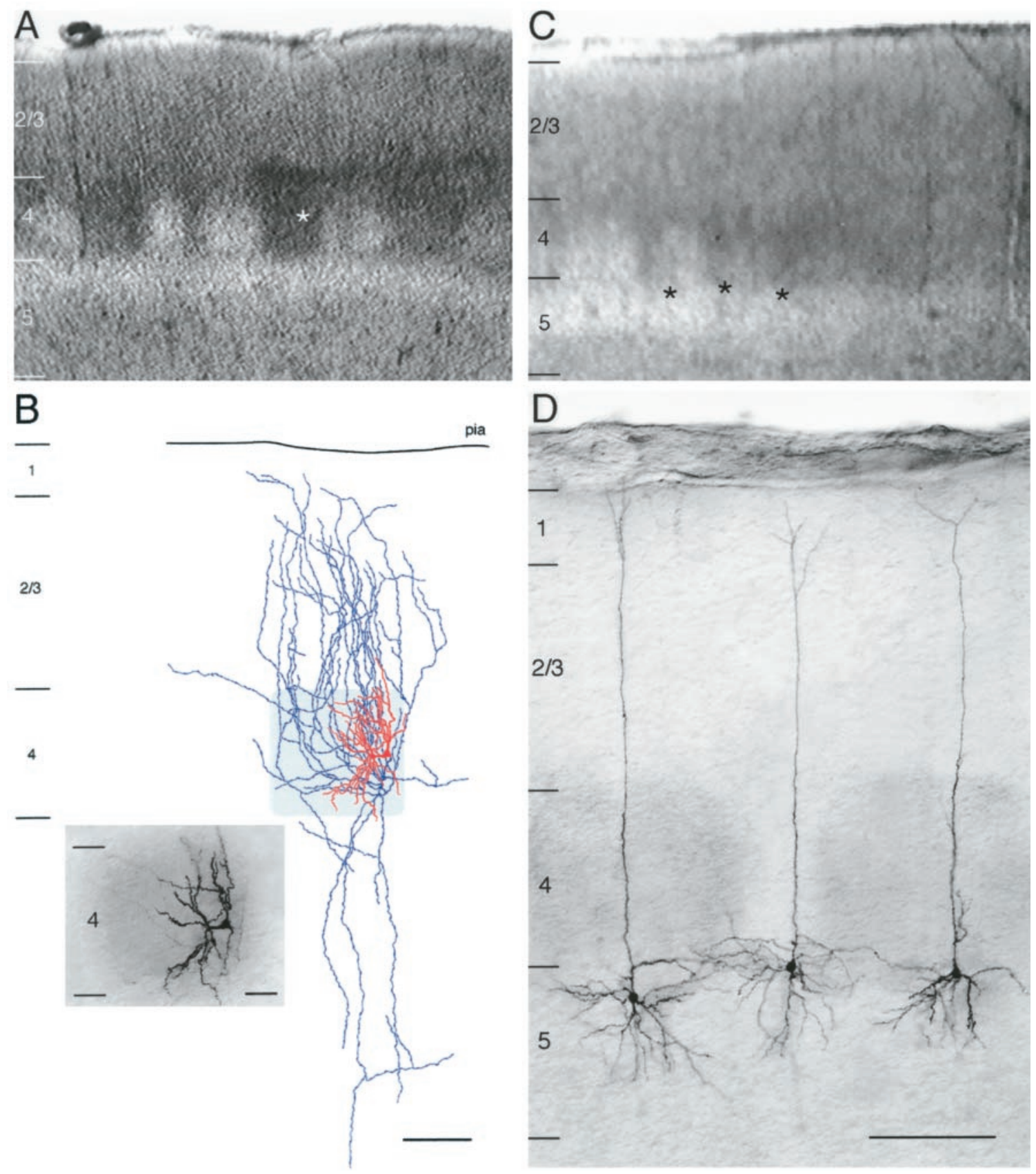

Figure 2. A, Barrel cortex slice under bright-field illumination. The white asterisk marks a biocytin-labeled spiny stellate cell. $B$, Camera lucida reconstruction of the spiny stellate cell marked by the white asterisk in $A$. The somatodendritic configuration is shown in red; the axonal collaterals are shown in blue. The outline of the barrel is revealed by the cytochrome oxidase staining and is shaded in light gray. Inset, Half-tone picture of the cytochrome oxidase and intracellular biocytin double staining of the same barrel. Scale bar: $100 \mu \mathrm{m}$; inset, $40 \mu \mathrm{m}$. $C$, Barrel cortex slice under bright-field illumination. The black asterisks mark the position of the biocytin-labeled pyramidal neurons shown in $D$. $D$, Row of biocytin-labeled pyramidal neurons in upper layer 5 . The somata of these neurons are located right beneath two adjacent barrels that were stained with cytochrome oxidase. In contrast to spiny stellate cells, the somatodendritic configuration of these neurons shows no obvious relation to the barrel structure. Scale bar, $200 \mu \mathrm{m}$.

rons. Biocytin-labeled pairs of synaptically coupled neurons were examined under the light microscope at high magnification. Only pairs for which a complete physiological analysis was made and that had no obvious truncation of their dendritic and axonal profiles were used for qualitative and quantitative morphology. Measurements were not corrected for shrinkage. Representative neuron pairs were photographed at various magnifications to document dendritic morphology, axonal projection, and location of synaptic contacts. The outline of neurons was then drawn with the aid of a camera lucida attached to an Olympus BX50 microscope (Olympus, Hamburg, Germany) at a final magnification of $720 \times$. For some pairs of neurons, three-dimensional reconstructions were also made at $400 \times$ magnification using the Neurolucida (Microbrightfield, Colchester, UK) software. The reconstructions provided the basis for further quantitative morphological analysis of the following parameters: (1) maximal horizontal field span of the dendrites and axons, (2) total number and distribution of putative synaptic contacts per neuron, (3) total number of boutons in cortical layers 1 to 6 , and (4) number of boutons per $100 \mu \mathrm{m}$ of axonal segment counted separately for each cortical layer. For all data, means \pm SD were calculated. Significance was tested using a two-tailed Student's $t$ test.

Cytochrome oxidase histochemistry. To identify the barrel structure in layer 4 of the somatosensory cortex, the cytochrome oxidase staining according to Wong-Riley (1979) was used on perfusion-fixed rat brains of the same age (postnatal day 12-15) as used for the acute slice preparations. In brief, animals were perfused transcardially with a PB solution containing $4 \%$ paraformaldehyde. Brains were stored overnight in the same fixative at $4^{\circ} \mathrm{C}$ and then prepared as described above. After several rinses in PB solution, free-floating 100- $\mu \mathrm{m}$-thick vibratome sections through the barrel field were incubated in a PB solution containing $50 \mathrm{mg}$ DAB, 15-30 $\mathrm{mg}$ cytochrome $c$, and $20 \mathrm{mg}$ catalase $/ 100 \mathrm{ml}$ at $37^{\circ} \mathrm{C}$ for $2 \mathrm{hr}$ in the dark. The reaction was stopped when individual barrels were clearly distinguishable from the background (see Fig. 1A). After several rinses in PB 

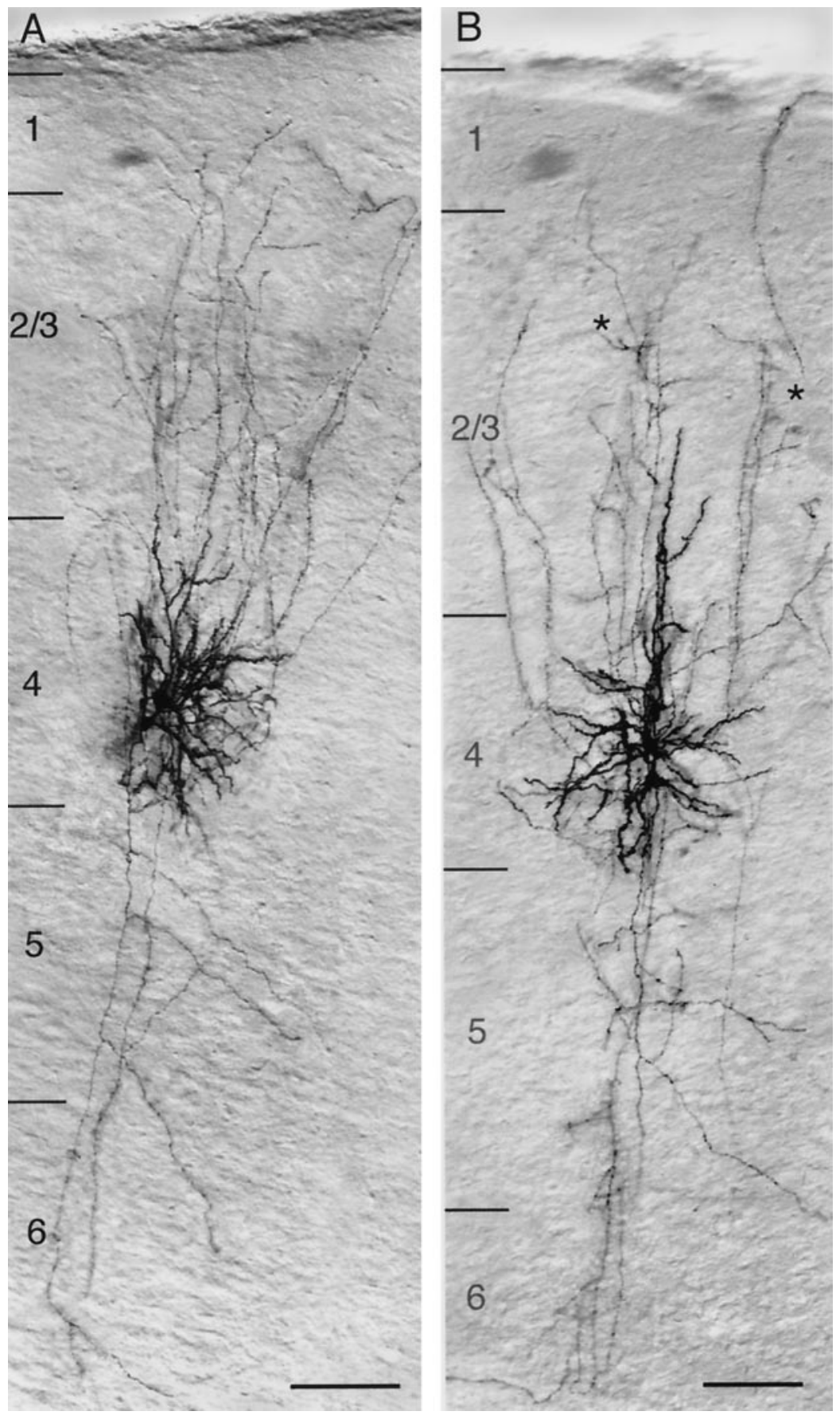

Figure 3. Low-magnification light microscope image of a synaptically coupled pair of spiny stellate cells $(A)$ and star pyramidal neurons $(B)$ filled with biocytin showing the location, dendritic configuration, and columnar axonal projection of both neurons. Note that the characteristic asymmetric dendritic configuration of spiny stellate cells is confined to layer 4, whereas the axons of the presynaptic and postsynaptic neuron project throughout the cortex from layer 1 to the white matter with extensive arborization in layers $2 / 3$ and 4 . In contrast, dendrites of star pyramidal neurons have no asymmetric distribution. They are largely confined to layer 4, with the exception of the apical dendrites that terminate in middle to upper layer $2 / 3$. The axons have a projection similar to that of spiny stellate cell axons but tend to show clustering (black asterisks) in layer $2 / 3$. Scale bar, $100 \mu \mathrm{m}$. solution, sections were mounted on glass slides, air-dried, defatted in absolute alcohol and xylene, finally embedded in Hyper-Mount (Life Science, Frankfurt, Germany), and coverslipped. In some experiments, cytochrome oxidase histochemistry and labeling of single biocytin-filled neurons ( $n=15$ neurons) were combined to reveal the dendritic and axonal organization with respect to the barrel structure (see Fig. $2 B$, inset, $D)$.

\section{RESULTS}

\section{Cytochrome oxidase stain of the barrel cortex slices}

All experiments were performed on thalamocortical slices in which the barrel structure in layer 4 is easily recognizable. Figure $1 A$ illustrates the barrel structure in somatosensory cortex as revealed by cytochrome oxidase staining that mirrors the bright-field images taken from acute slice preparations of the barrel cortex. Combined bright-field and IR-DIC videomicroscopy at low and high magnification, respectively, showed that the somata of neurons appeared to be organized in clusters of 5-15 neurons (Fig. $1 B, C$ ), with a predominant location at the edges of individual barrels. In contrast, spiny stellate neurons in the visual cortex display a more homogeneous distribution throughout layer 4 (LeVay, 1973; Lund, 1984; Martin and Whitteridge, 1984, 1988).

Multiple biocytin labeling of individual neurons in combination with cytochrome oxidase staining ( $n=15$ neurons) revealed that almost the entire dendritic and axonal domain of excitatory spiny neurons in layer 4 was confined to a single cortical column. This was found for all spiny layer 4 neurons in the barrel field (Fig. $2 A, B)$. In contrast, layer 5 pyramidal neurons $(n=5)$ injected right below the barrels showed a completely different morphology, and their apical dendrites showed no obvious relationship to the barrels as defined with cytochrome oxidase staining (Fig. 2C,D).

\section{Morphology of synaptically coupled spiny layer 4 neurons}

Excitatory layer 4 neurons were identified by their shape in IR-DIC and their "regular" pattern of action potentials after current injec- 
Figure 4. Camera lucida reconstruction of the pair of spiny stellate cells shown in Figure $3 A$. For clarity, the presynaptic and postsynaptic neurons were separated. The dendritic configuration of the neurons is drawn in red and black for presynaptic and postsynaptic neurons, respectively. The axonal arborization is drawn in blue (presynaptic neuron) and green (postsynaptic neuron). The gray shading delineates the barrel structure. Note the dense projection of axon collaterals in layer $2 / 3$. Scale bar, $100 \mu \mathrm{m}$.
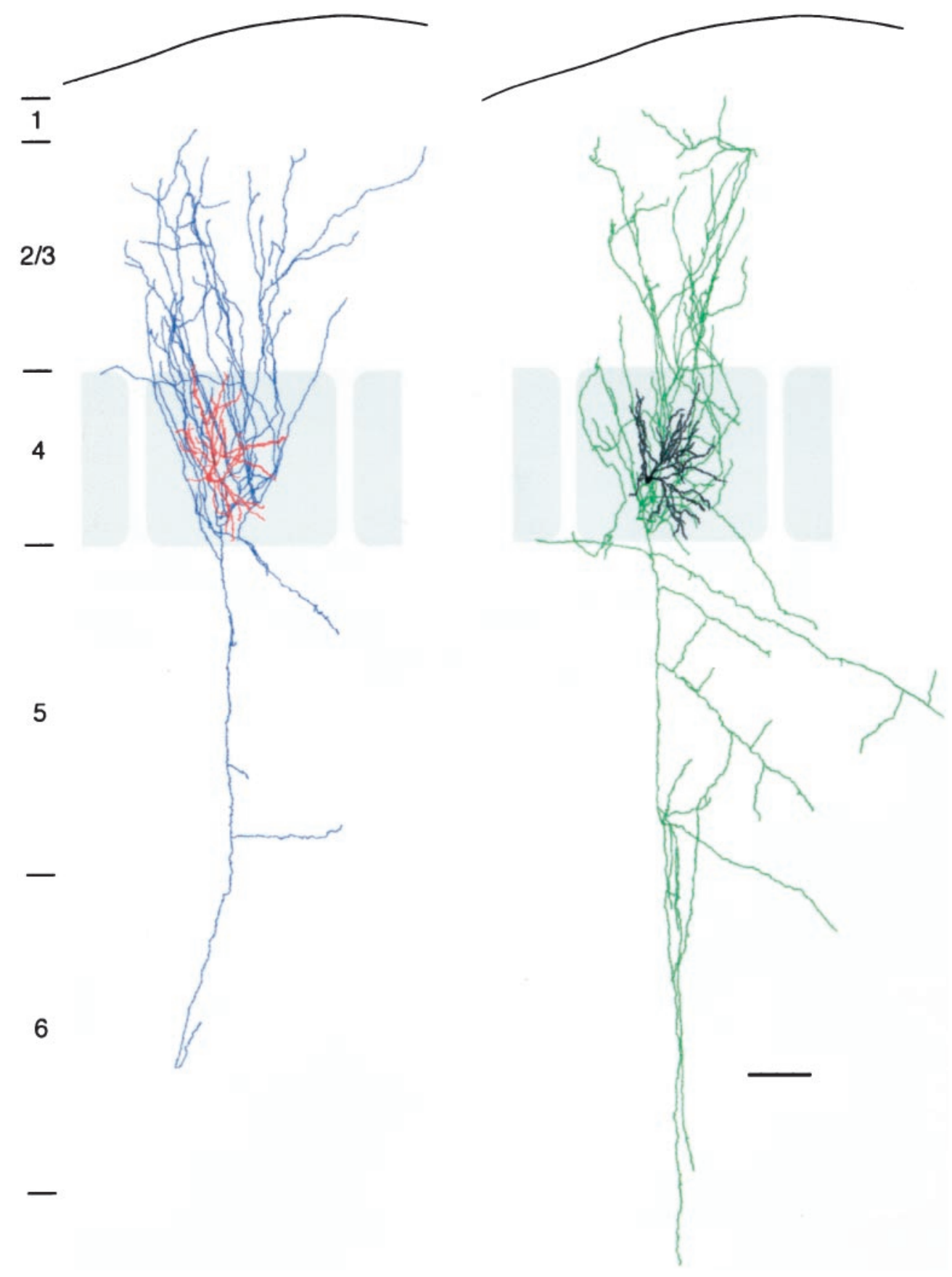

$2 / 3$
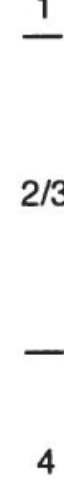

5

4

6
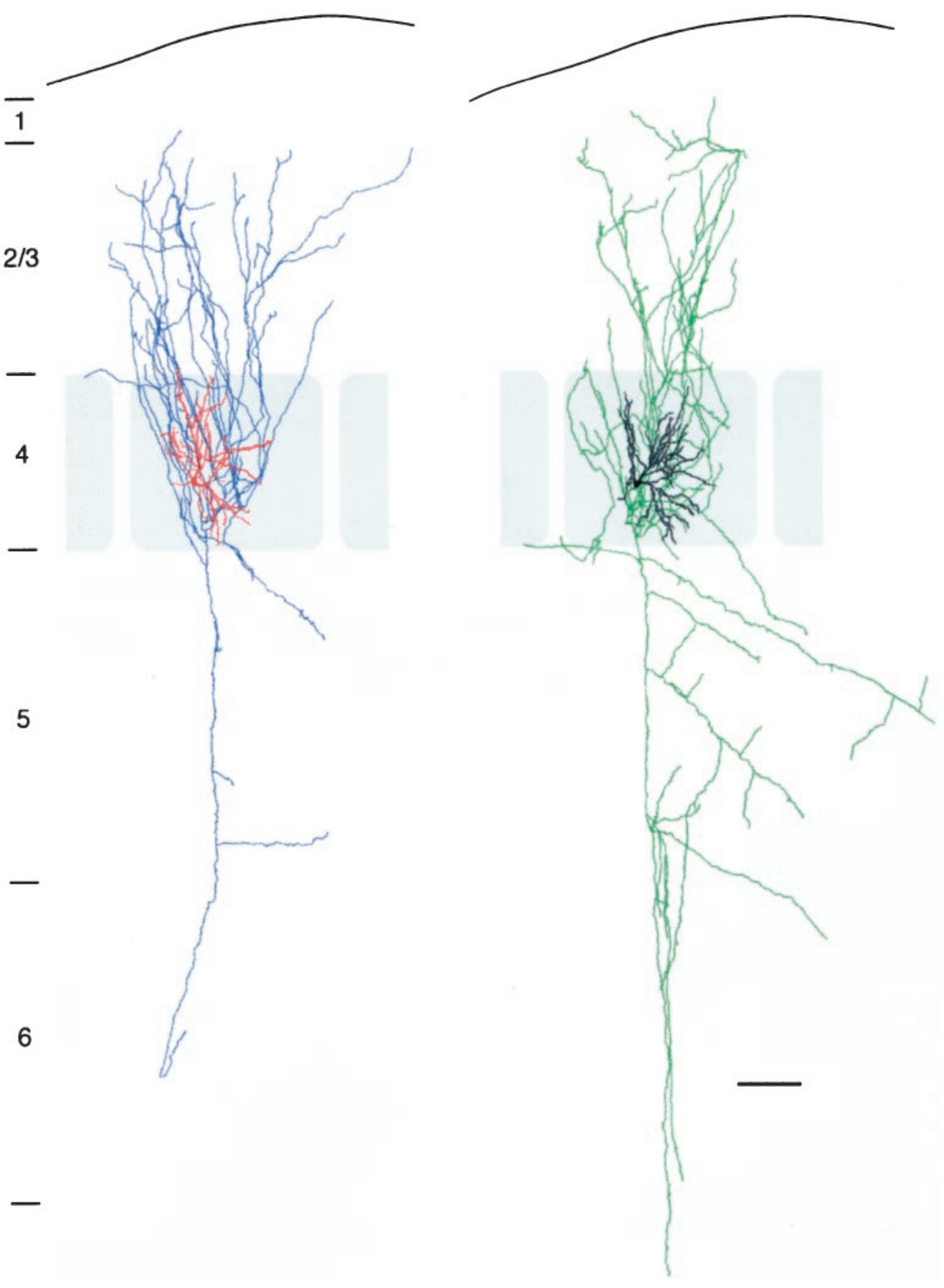

3

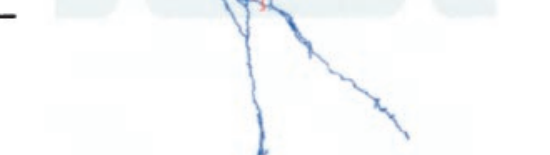

$-$
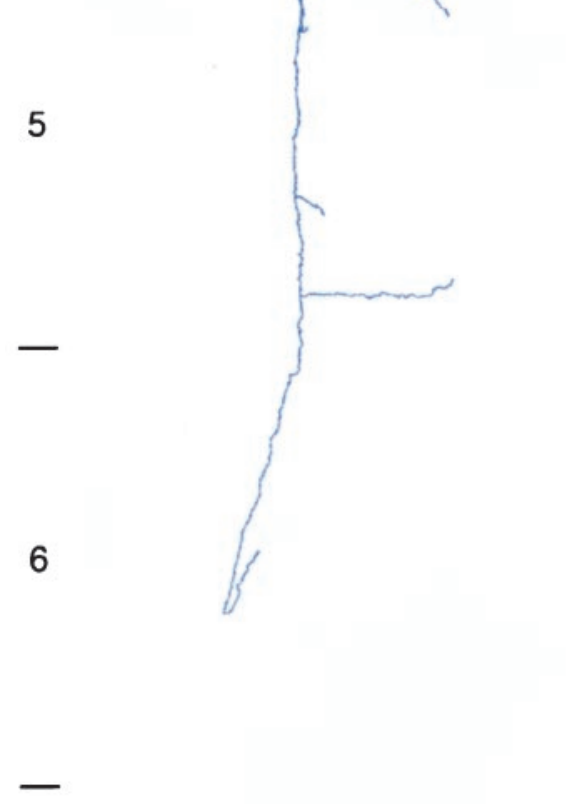

tion (Connors and Gutnick, 1990; Feldmeyer et al., 1999b). Spiny layer 4 neurons, i.e., spiny stellate and star pyramidal cells, were easily distinguished by their spherical to ovoid somata and the absence of a prominent apical dendrite (Fig. $1 C$ ). In addition, their somata appeared to be larger than those of GABAergic aspiny stellate layer 4 interneurons ( $\geq 10 \mathrm{vs} \leq 10 \mu \mathrm{m}$ ) but smaller than that of GABAergic interneurons with fusiform somata $(>20 \mu \mathrm{m})$. Monosynaptic connections between spiny layer 4 neurons were reliable and characterized by a low coefficient of variation and a low failure rate of unitary EPSPs (Feldmeyer et al., 1999b).

From the sample of synaptically connected pairs of spiny neurons in layer $4(n=131), \sim 80 \%$ were identified as spiny stellate neurons and the remainder as star pyramidal neurons. However, often no clear distinction between the two cell types was possible because of the variability in the morphology and length of the apical dendrite. Representative examples of pairs of coupled spiny stellate (nine cell pairs) and star pyramidal neurons (two cell pairs) were selected for further analysis.

\section{Spiny stellate cells}

Spiny stellate cell dendrites in the barrel cortex have a characteristic asymmetric orientation (Figs. $2 B, 3 A, 4,5$ ), in contrast to spiny stellate cells in layer 4 of the visual cortex that generally display a multipolar, almost radially symmetric dendritic field (LeVay, 1973; Lund, 1984; Martin and Whitteridge, 1984; 1988; but see Katz et al., 1989; Kossel et al., 1995). Three to six thick primary dendrites emerged from the spherical to ovoid somata that gave rise to several secondary, tertiary, and higher-order dendrites. These dendrites formed an asymmetric dendritic field of various size (Table 1) that was confined to a single barrel and always oriented toward its center (Figs. $2 B, 3 A, 4)$. Higher-order dendrites were densely covered with spines (Fig. 5). Spiny stellate cells that were synaptically coupled to each other as described here resembled those designated as class I spiny neurons in the barrel cortex by Woolsey and coworkers (Pasternak and Woolsey, 1975; Simons and Woolsey, 1984). 

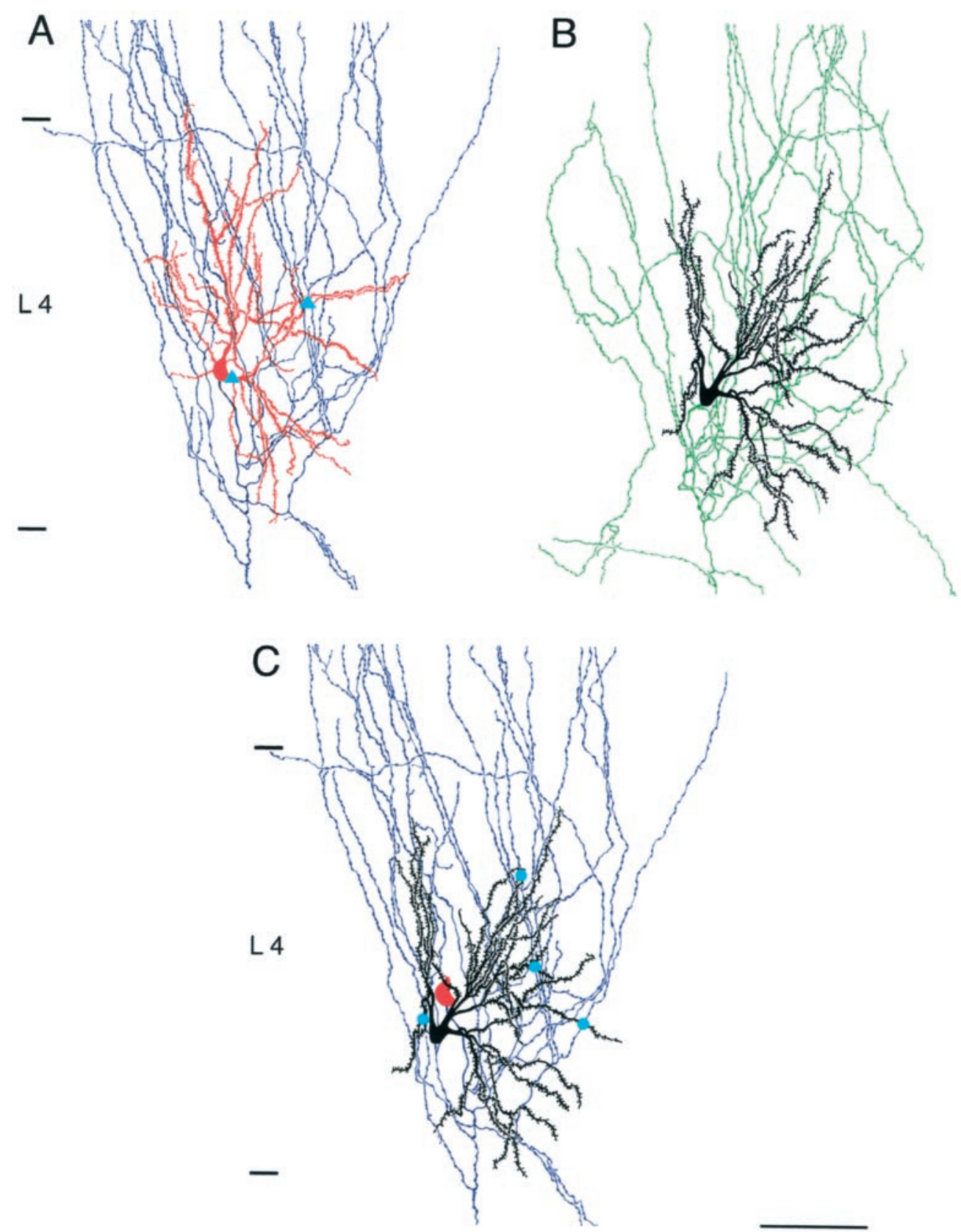

Figure 5. Camera lucida reconstruction of the same pair of spiny stellate cells as shown in Figures $3 A$ and $4 . A$, The projecting neuron (cell 1 ) with its dendritic arbor in red and the axon in blue. B, The target neuron (cell 2) with its dendritic arbor in black and the axon in green. Putative autaptic contacts between axon and dendrites of the presynaptic cell are marked with blue triangles. $C$, Dendritic arbor of cell 2 (target neuron) and axonal projections of cell 1 (projection neuron). Blue dots indicate putative synaptic contacts between the presynaptic axon and the dendrites of the postsynaptic spiny stellate cell as identified by high-power light microscopic examination. The soma of the presynaptic cell is shown in red. Autaptic contacts are not marked in $C$. Scale bar, $100 \mu \mathrm{m}$.

The axonal collaterals of spiny stellate cells project throughout all cortical laminae from layer 1 to the white matter (Figs. $3 A, 4$ ) and remain largely confined to a single cortical column. The main axon emerges from the soma and descends toward the white matter, giving rise to numerous collaterals. Most of these collaterals branch off in layer 4 and ascend toward layer $2 / 3$. In layers 5 and 6 , a few long horizontal collaterals (length 500-800 $\mu \mathrm{m}$ ) were observed that may project to adjacent cortical columns. The densest axonal projection was found in layers 4 and $2 / 3$ where the axons show a high degree of collateralization. In these layers most of the axonal collaterals were confined to a single cortical column (Fig. 4). Their orientation is predominantly vertical in layers $2 / 3$ and 4 , whereas in layers 5 and 6 they follow a slightly descending horizontal course (Figs. $3 A, 4$ ).
Putative synaptic contacts (two to five) (Feldmeyer et al., 1999b) were distributed over the entire dendritic tree but preferentially located on tertiary dendrites and relatively close to the soma (Fig. $5 C$ ). In addition, potential autaptic contacts were identified that displayed a similar dendritic distribution as the synapses.

To estimate the number of postsynaptic target neurons contacted by a single spiny stellate cell, the total number of synaptic boutons was counted separately for each cortical layer (Table 2). More than $75 \%$ of all synaptic boutons were found in layers 4 and $2 / 3$, with the highest density in layer $2 / 3$; the remaining $25 \%$ of synaptic boutons were found in layers 5 and 6 (Table 2). This result suggests that the main target cells of spiny stellate cell axons are spiny neurons in layer 4 and pyramidal neurons in $2 / 3$, implying that the flow of excitation is preferentially directed from layer 4 to layer $2 / 3$. This 
Table 1. Quantification of dendritic and axonal length of excitatory spiny neurons in layer 4

\begin{tabular}{lrr} 
& Mean & \multicolumn{1}{c}{ SD } \\
\hline Soma diameter $(\mu \mathrm{m})$ & 13.2 & 1.2 \\
Number of dendrites & 3.9 & 1.1 \\
Mean dendritic length $(\mu \mathrm{m})$ & 468.0 & 92.1 \\
Dendritic field span $(\mu \mathrm{m})$ & 194.1 & 39.2 \\
Total axonal length $(\mu \mathrm{m})$ & 6404.8 & 2426.6 \\
Horizontal field span of axons in layer 4 $(\mu \mathrm{m})$ & 302.3 & 146.5 \\
Horizontal field span of axons in layer 2/3 $(\mu \mathrm{m})$ & 403.6 & 75.7 \\
Vertical field span of axon $(\mu \mathrm{m})$ & 996.4 & 237.0 \\
\end{tabular}

Because there were only two pairs of star pyramidal neurons, data from spiny stellate cells and star pyramidal neurons were pooled.

view is further substantiated by the fact that the number of synaptic boutons per $100 \mu \mathrm{m}$ axonal segment was significantly higher $(p>$ 0.01 ) in layers $2 / 3$ and 4 than in the other layers (Table 3 ). Although we cannot exclude the possibility that boutons may also synapse on apical oblique dendrites of infragranular pyramidal neurons, the preferential termination of spiny stellate boutons appears to be on neurons in these layers.

\section{Star pyramidal neurons}

The second class of synaptically coupled excitatory neurons resembled those designated as star pyramidal cells (Lund, 1984; for review, see Lund, 1988). These neurons constitute a smaller fraction $(\sim 20 \%)$ of the spiny neurons in layer 4 of the barrel cortex. Somata and dendritic domains of star pyramidal neurons were also exclusively located within layer 4 , with the exception of the prominent apical dendrite. Its distal part often ascends to layer $2 / 3$, but without forming a terminal tuft (Figs. $3 B, 6$ ). In contrast to spiny stellate cells, star pyramidal cells never showed an asymmetry of the dendritic arbor (Figs. 3B, 6). Three to seven primary basal dendrites emerge from the spherical to ovoid soma that give rise to secondary, tertiary, and higher-order basal dendrites of various lengths. Most of the dendrites were restricted to a single barrel. The thick apical dendrite emerges from the upper pole of the soma and ascends through layer 4 , giving rise to several oblique apical dendrites (Figs. 3B, 6). The number and distribution of synaptic and autaptic contacts were similar to those of spiny stellate cells (see also Feldmeyer et al., 1999b, their Table 2).

The axons of star pyramidal cells projected also into all cortical layers (1-6) but spared the white matter (Figs. 3B,6). As shown for spiny stellate cells, axonal collaterals were largely confined to a single cortical column. The main axon emerges either directly from the soma or from one of the primary basal dendrites and descends toward the white matter. In some neurons the main axon was seen to loop back toward layer 4 after reaching layer 6 . The main axon gives rise to numerous collaterals ascending vertically toward layer 1. Only a few but long collaterals (up to $700 \mu \mathrm{m}$ ) were observed to descend to layers 5 and 6 (Figs. $3 B, 6$ ). Again, the most dense axonal projection was established in layers 4 and $2 / 3$, but the density of collaterals and the degree in branching of the axonal collaterals were lower when compared with the axonal arborization of spiny stellate cells (compare Figs. 4 and 6). In layer 4, axonal collaterals are largely confined to a single barrel, whereas in upper layer $2 / 3$ they fan out so that a few appear to project to adjacent cortical columns (Figs. $3 B, 6$ ). In upper layer $2 / 3$ axonal collaterals were often organized in clusters, as described for pyramidal cells of cortical laminae 2/3 and 5 (Fig. 3B) (see also Gilbert and Wiesel, 1979). The total number of synaptic boutons on the axons of star pyramidal cells was significantly lower than that of spiny stellate cells (Table 2). This may be related to the lower number of axonal collaterals, because the number of boutons per $100 \mu \mathrm{m}$ axonal segment was similar to that of spiny stellate cells $(p>0.01)$ (Table $3)$. Again, most of the synaptic boutons $(\sim 70 \%)$ were found in layers 4 and $2 / 3$, with the highest density in layer $2 / 3$ (Table 2). The number of synaptic boutons per $100 \mu \mathrm{m}$ axonal segment was also significantly higher $(p>0.01)$ in layers $2 / 3$ than in layers 4 and 5 (Table 3). As observed for spiny stellate cells, star pyramidal neurons establish synaptic contacts predominantly with neurons in superficial layers 4 and $2 / 3$ of the barrel cortex or superficial dendritic segments of infragranular pyramidal neurons traversing through these layers. This notion is supported by paired recordings between spiny layer 4 neurons and layer $2 / 3$ pyramidal cells of the barrel cortex (Feldmeyer et al., 1999a).

\section{Postsynaptic target structures of excitatory spiny neurons in layer 4 of the barrel cortex}

The number of axonal collaterals as well as the density of synaptic boutons was highest in layers 4 and 2/3, suggesting that the main

Table 2. Quantification of total number of boutons according to the different cortical layers

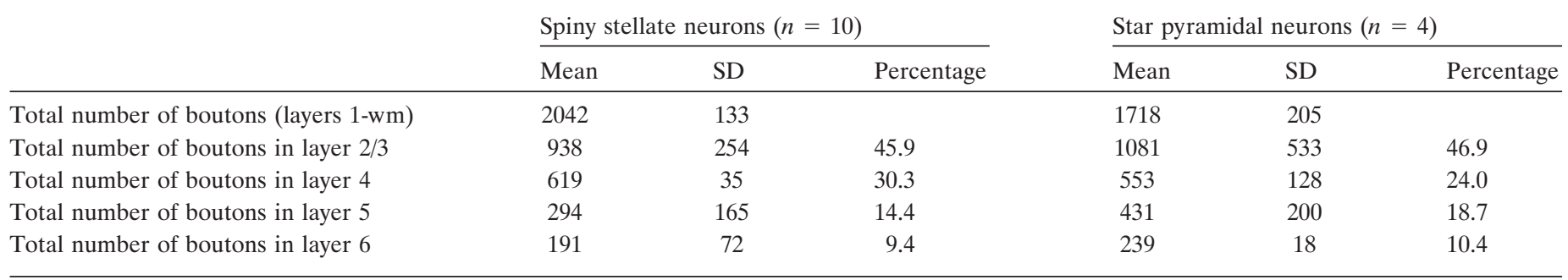

Table 3. Quantification of bouton density per $100 \mu \mathrm{m}$ axonal length according to the different cortical layers

\begin{tabular}{|c|c|c|c|c|}
\hline & \multicolumn{2}{|c|}{ Spiny stellate neurons } & \multicolumn{2}{|c|}{$\underline{\text { Star pyramidal neurons }}$} \\
\hline & Mean & SD & Mean & SD \\
\hline Boutons per $100 \mu \mathrm{m}$ in layer $2 / 3$ & 20.6 & 2.3 & 20.1 & 3.1 \\
\hline Boutons per $100 \mu \mathrm{m}$ in layer 4 & 18.4 & 2.9 & 17.1 & 3.7 \\
\hline Boutons per $100 \mu \mathrm{m}$ in layer 5 & 15.9 & 2.7 & 17.0 & 2.7 \\
\hline Boutons per $100 \mu \mathrm{m}$ in layer 6 & 15.1 & 3.2 & 18.6 & 3.5 \\
\hline
\end{tabular}

In each cortical layer 50 axonal segments were randomly examined. Significant differences were tested using a two-tailed Student's $t$ test $(p>0.05)$. 


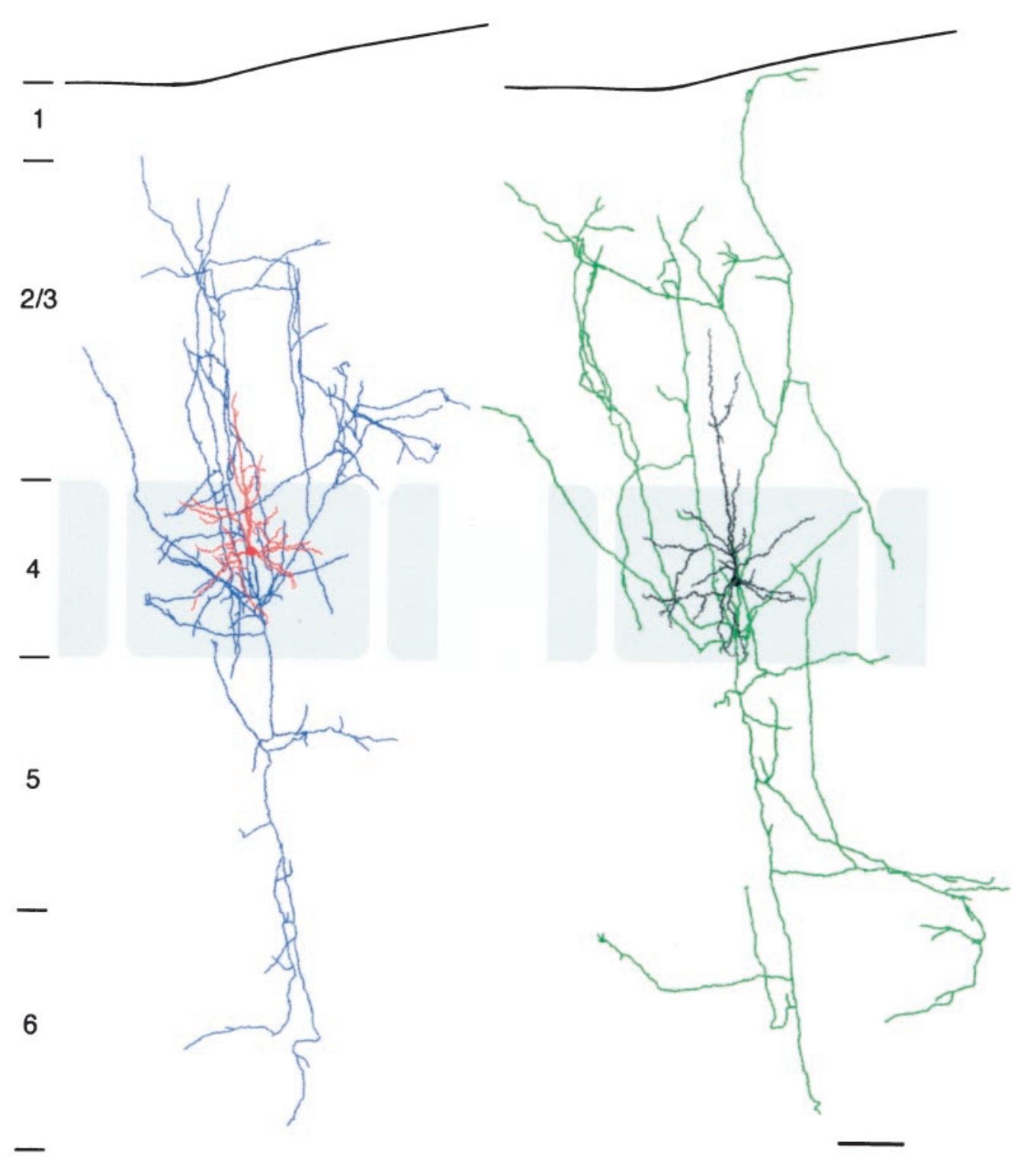

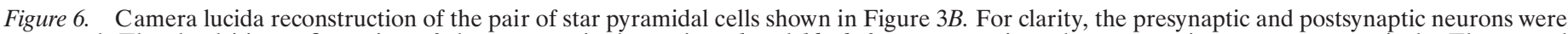

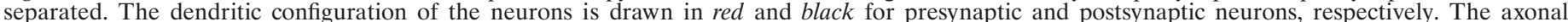

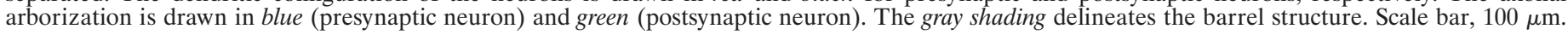

stream of excitation via spiny layer 4 neurons is directed to these layers. Synaptic contacts established by the axons of biocytinlabeled spiny neurons $(n=3)$ in layer 4 of the barrel cortex with postsynaptic target structures in layers 4 and $2 / 3$ were examined in serial ultrathin sections. Of the total number of boutons investigated $(n=200 ; 75$ in layer 4 and 125 in layer $2 / 3)$, the vast majority of the target structures in layers 4 and $2 / 3$ were excitatory spiny neurons. This could explain the high probability in electrophysiological experiments of finding connected pairs of excitatory spiny neurons in layer 4 or between layers 4 and 2/3 (Feldmeyer et al., $1999 a, b)$. In layer 4 , most of the synaptic contacts $(n=55)$ were found on small caliber dendritic shafts (Fig. 7C,D) and a smaller fraction $(n=20)$ on dendritic spines (Fig. $7 A)$ of other spiny neurons. In layer $2 / 3$, synaptic contacts were formed with either small caliber dendritic shafts $(n=57)($ Fig. $7 F)$ or spines $(\mathrm{n}=63)$ (Fig. $7 E, G$ ) of putative basal dendrites of layer $2 / 3$ pyramidal neurons $(n=120)$ and on a smaller fraction with thick caliber apical dendrites $(n=5)$ of either layer $2 / 3$ or layer 5 pyramidal neurons (Fig. $7 H$ ).

In addition, on every third grid, GABA postembedding immunogold labeling was performed to further identify GABAergic target structures of biocytin-labeled excitatory spiny cell axons. In the sample investigated ( $n=60$ sections), no biocytin-labeled boutons were found that synapsed on GABAergic profiles. However, in the same sample, GABAergic structures such as synapses, dendritic profiles, and somata that were not contacted by biocytinlabeled boutons could be easily identified (data not shown). Again, this finding suggests that the main target structures of excitatory spiny neurons are other excitatory spiny neurons in layer 4 and pyramidal neurons in layer $2 / 3$.

\section{DISCUSSION}

The dendritic geometry, the axonal projections, and the postsynaptic target structures of excitatory spiny neurons in layer 4 of the barrel cortex provide the morphological basis for their functional role in the microcircuitry of a cortical column. We have sharpened the morphological picture of the excitatory microcircuits by using dual recording from synaptically connected pairs and subsequent characterization of the morphology of the spiny layer 4 neurons.

The results show that the dendritic arbor of synaptically coupled spiny layer 4 neurons is largely confined to a single barrel in layer 4 and that both synaptic and autaptic contacts were exclusively found within a barrel in layer 4, whereas their axon collaterals project throughout all cortical layers. The axonal collaterals were 

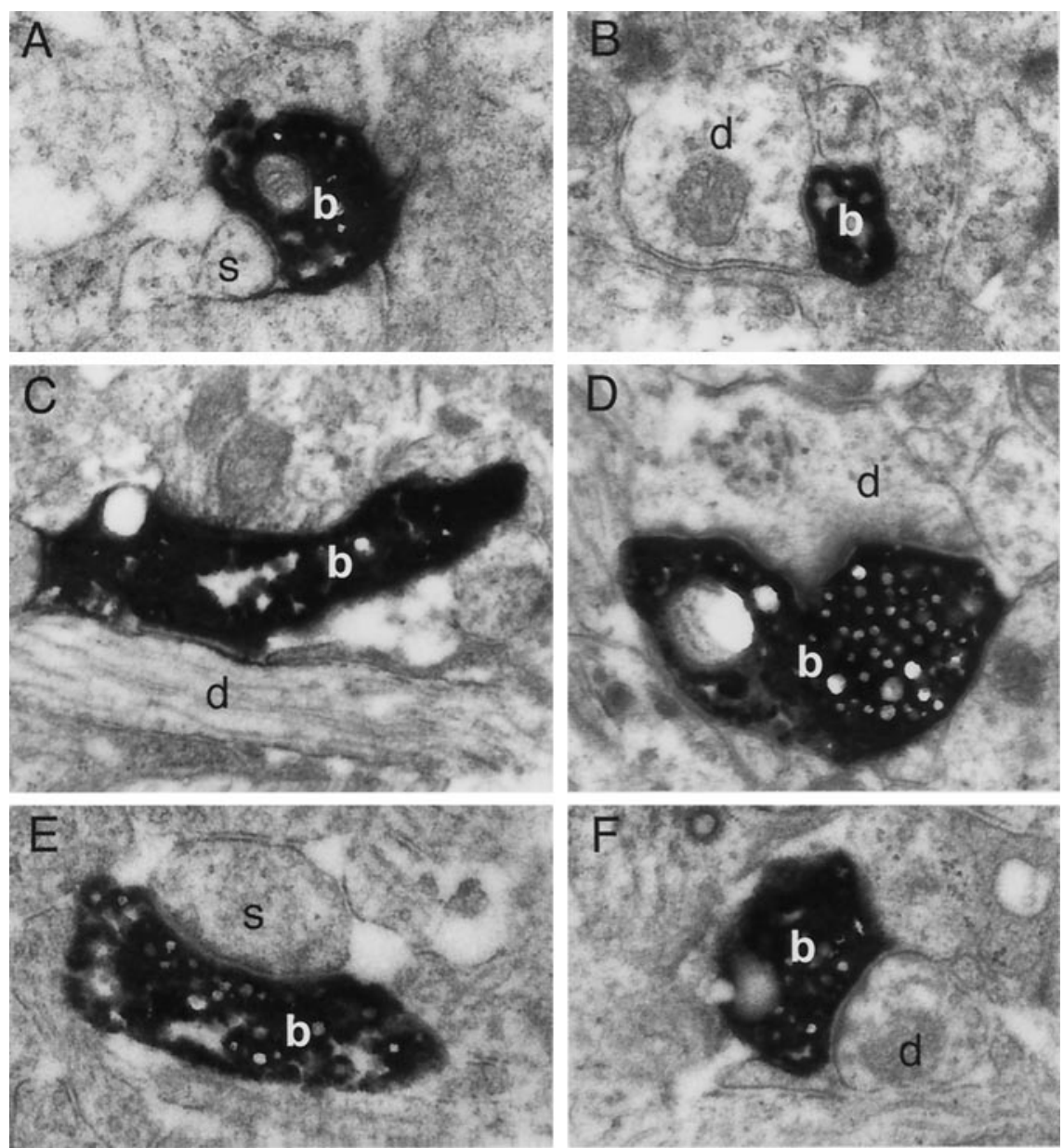

Figure 7. Electron microscopy of synaptic contacts established by spiny stellate neurons on different postsynaptic target structures in layers $4(A-D)$ and $2 / 3(E-H)$ as revealed from serial ultrathin sectioning through the entire axonal domain. Boutons $(b)$ of synaptic contacts established by the axon of a biocytin-labeled spiny stellate neuron on $(A)$ a spine $(s)$ or $(B-D)$ small caliber dendritic shafts $(d)$ of excitatory neurons, presumably other spiny stellate neurons $(E-H)$. Synaptic contacts established by the axon of a biocytin-labeled spiny stellate neuron on $(E, G)$ spines, $(F)$ a small caliber dendritic shaft of basal dendrites, and $(H)$ an apical dendrite $(a d)$ of presumed pyramidal neurons in layer $2 / 3$. Scale bar, $0.5 \mu \mathrm{m}$.
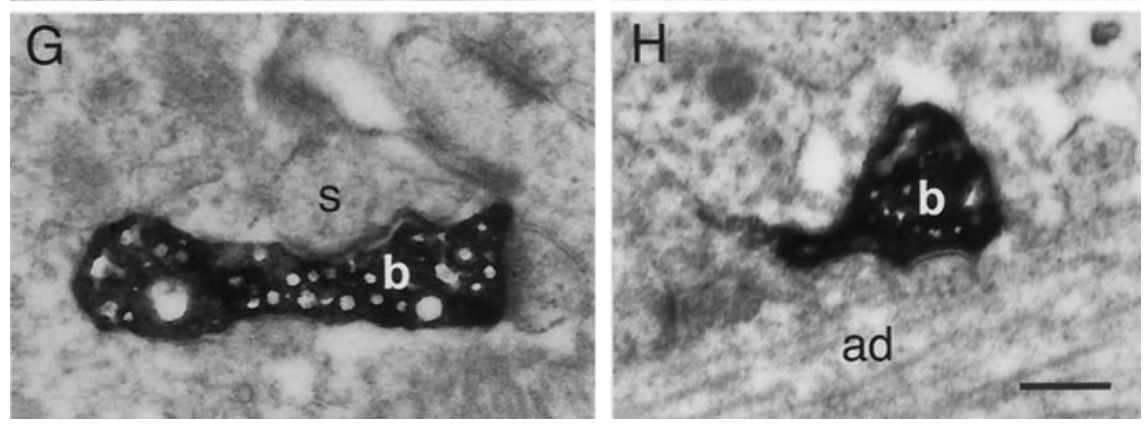

also largely confined to a single cortical column in the granular and supragranular layers. However, a few horizontal collaterals in layers $2 / 3,5$, and 6 project to adjacent cortical columns. The total number of synaptic boutons and their density per unit length of axon were highest in layers $2 / 3$ and 4 . These morphological findings suggest that the main target neurons of a spiny neuron in layer 4 are other excitatory spiny neurons in layer 4 of the same barrel and pyramidal neurons in layer $2 / 3$ of the same cortical column (Feldmeyer et al., 1999a,b), and probably to a lesser extent pyramidal neurons in infragranular layers 5 and 6.

\section{Axonal projection pattern and dendritic morphology of spiny layer 4 neurons}

The axonal projection of spiny layer 4 neurons in the barrel cortex is highly organized with respect to the structure of a cortical column. In a quantitative Golgi study, Harris and Woolsey (1983) have shown that the main axonal trunk of class I neurons (corresponding to spiny layer 4 neurons) is directed toward the white matter, with recurrent collaterals projecting back into the barrels. Axonal projections to infragranular and supragranular layers were not reported, which may be attributable in part to the different plane of sectioning and incomplete staining of axonal collaterals by the Golgi method. Whole-cell recording in combination with intracellular biocytin labeling in the oblique coronal slice (Agmon and Connors, 1991) made it possible to describe the axonal projections of spiny layer 4 neurons in more detail.

The axonal projections of spiny layer 4 neurons in the visual cortex are well documented, in contrast to the barrel cortex (Martin and Whitteridge, 1984; Lund, 1988; Burkhalter, 1989; Ahmed et al., 1994). Spiny stellate and star pyramidal cells show a multitude of axonal projection patterns. Axons can either be more locally organized or display a patchy and extensive (2.5 mm lateral spread) tangential projection (Martin and Whitteridge, 1984, their Figures $8-10)$. This variability in projection patterns in layer 4 could be explained by the different information processing pathways for somatic/visceral and visual information as well as by different organization at the level of cortical layer 4 (barrels vs ocular dominance columns).

The dendritic arborization pattern of spiny neurons in layer 4 has been studied in detail previously (Pasternak and Woolsey, 1975; Woolsey et al., 1975; Steffen, 1976; Steffen and van der Loos, 1980; 
Harris and Woolsey, 1981; Simons and Woolsey, 1984). Asymmetry of the dendritic arborization has been noted for some but not all spiny layer 4 neurons (class I neuron). In this study, nearly all spiny stellate cells $(\sim 95 \%)$ that were investigated showed a clear asymmetry, whereas star pyramidal neurons with a characteristic main apical trunk display a radially symmetric distribution of their basal dendrites. This classification was possible because the oblique coronal plane of sectioning allowed discrimination of spiny stellate and star pyramidal neurons in contrast to the tangential plane used in Golgi studies (Pasternak and Woolsey, 1975; Woolsey et al., 1975; Steffen, 1976; Simons and Woolsey, 1984). Because the axonal and the dendritic field span of a spiny stellate cell show a strong overlap and cover one-third to two-thirds of a barrel $(\sim 200-400 \mu \mathrm{m}$ in diameter), the strong asymmetry of the dendritic field could result in segregation of the inputs within an individual barrel. This appears to be unlikely for star pyramidal cells with a more radially symmetric dendritic field. In addition, these neurons may receive additional synaptic input via their apical dendrites.

\section{Flow of excitation in the barrel cortex \\ Granular layer}

The target structures of thalamic afferents arising from the ventroposterior medial nucleus are excitatory spiny neurons and different GABAergic interneurons in layer 4 (White et al., 1984; Benshalom and White, 1986). Apart from thalamic input, these neurons receive excitation from intracortical sources, namely other spiny layer 4 neurons and layer 6 pyramidal neurons (Benshalom and White, 1986). However, the contribution of thalamocortical versus intracortical projections to the excitatory drive of spiny layer 4 neurons is still a matter of debate. It has been demonstrated that thalamocortical afferents to spiny layer 4 neurons in the barrel cortex are characterized by a high reliability, whereas intracortical connections are supposedly of low reliability (Gil et al., 1999). However, synaptic transmission between individual spiny layer 4 neurons has a low failure rate, a low coefficient of variation, and a high connectivity (Feldmeyer et al., 1999b). This suggests that intracortical inputs serve to enhance even weak thalamic activity; the main excitatory drive thus appears to be generated intracortically (Douglas et al., 1995; Stratford et al., 1996; Feldmeyer et al., 1999b). Evidence supporting this hypothesis comes from Ahmed et al. (1994) who reported a more than fourfold preponderance of intracortical over thalamocortical inputs to spiny stellate neurons of cat visual cortex. Furthermore, Stratford et al. (1996) and TarczyHornoch et al. (1999) found that both thalamocortical and intracortical (spiny stellate-spiny stellate connections) have a high reliability similar to those found in the somatosensory cortex.

\section{Supragranular layers}

Spiny layer 4 neurons subsequently relay excitation to layer $2 / 3$ but because of the largely columnar organization of the axons of these neurons it remains restricted to neurons within the same cortical column (Feldmeyer et al., 1999a,b). This finding is further supported by optical recordings of voltage-sensitive dyes, which have shown that excitatory activity evoked by stimulation of thalamocortical afferents is largely restricted to a single barrel whereas in layer 2/3 it spreads across cortical columns (Laaris et al., 2000). It may be speculated that in layer $2 / 3$ excitation arriving from layer 4 is distributed by pyramidal cell axons throughout the primary somatosensory cortex in vertical and horizontal directions (for review, see DeFelipe and Farinas, 1992). In supragranular layers, the spread of excitation may be no longer confined to a cortical column but mostly lateral to adjacent or even more distant cortical columns (Fig. 8). Furthermore, excitatory activity is probably not restricted to one hemisphere but also relayed by the commissural axons of layer $2 / 3$ pyramidal neurons via the corpus callosum to the other hemisphere (DeFelipe and Farinas, 1992). This may help to correlate and balance sensory input from the ipsilateral and the contralateral whisker pad. Obviously this spread of excitation depends mostly on the functional properties of spiny stellate and pyramidal cells that will filter excitation, depending on the
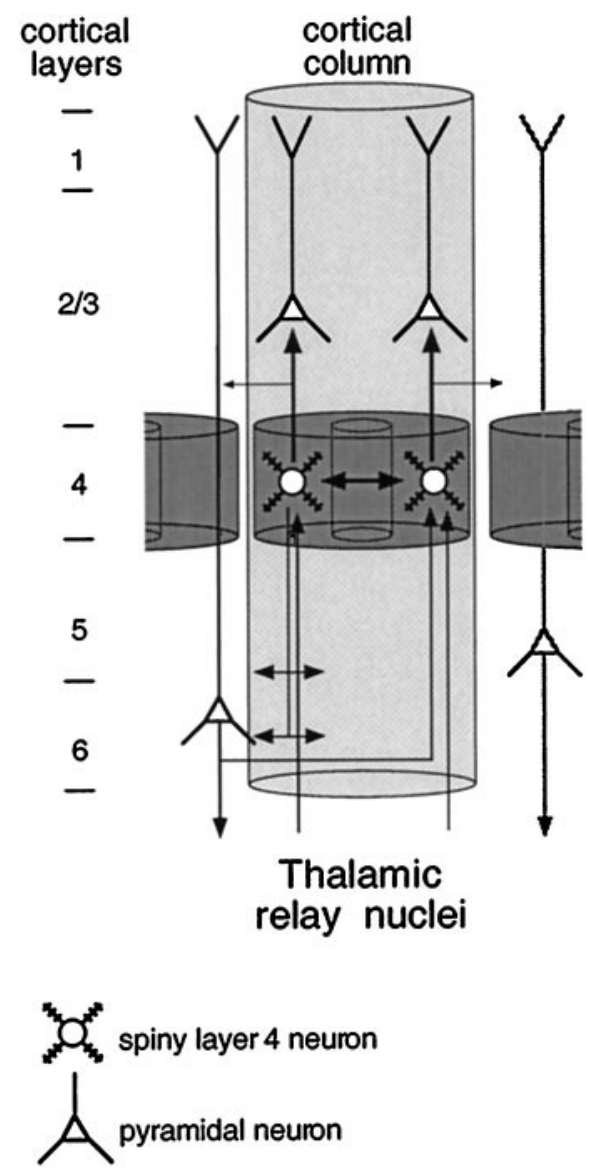

Figure 8. Simplified schematic diagram of the flow of excitation within a cortical column. At the level of layer 4, individual barrels are shown in dark gray. A functional cortical column is superimposed in light gray. Excitatory input coming from thalamic relay nuclei is relayed and amplified in layer 4 by excitatory spiny neurons with strong synaptic connections as indicated by the thick arrow. No distinction was made between spiny stellate and star pyramidal neurons because they have similar axonal projection patterns. Through the vertical axonal collaterals of these neurons that have a preferential projection toward superficial layers, excitation is then transmitted to layer $2 / 3$ pyramidal neurons and finally distributed throughout the barrel cortex via the long-range tangential axons of layer $2 / 3$ pyramidal cells. Thickness of arrows indicates the preferential projections of the axons, in particular for the spiny layer 4 neurons. Note that there are only weak tangential projections to adjacent barrels. To reduce complexity, cortical inhibition mechanisms and thalamic input to layers 5 and 6 have been omitted.

frequency-dependent transmission properties (i.e., short-term plasticity) and spatial and temporal coincidence of synaptic activity in these neurons (Egger et al., 1999). This may represent the initial step in the cortical integration of afferent sensory signals from several whiskers. This proposal is supported by in vivo 2-deoxyglucose mapping and imaging studies showing that the tangential spread of excitation occurs indeed at the level of layer $2 / 3$ (McCasland and Woolsey, 1988; Kleinfeld and Delaney, 1996; Woolsey et al., 1996). Finally, layer $2 / 3$ pyramidal cells can excite layer 5 pyramidal cells, the principal output neurons of the neocortex (Thomson and Bannister, 1998; Reyes and Sakmann, 1999).

\section{Infragranular layers}

In analogy to the visual cortex, spiny layer 4 neurons may also establish synaptic contacts with layer 6 pyramidal neurons and in turn may receive synapses from these neurons (Gilbert and Wiesel, 1979; Martin and Whitteridge, 1984; McGuire et al., 1984; Benshalom and White, 1986; Ahmed et al., 1994; Stratford et al., 1996; Tarczy-Hornoch et al., 1999). The axonal projection of spiny layer 4 neurons toward layer 6 makes it likely that such a feed-forward 
loop exists also in the somatosensory cortex and may also serve to control the flow of excitation.

\section{Inhibitory neurons}

The flow of excitation within a cortical column is controlled by a very heterogeneous population of GABAergic interneurons in each layer (Somogyi et al., 1998; Gupta et al., 2000). Based on the location of GABAergic synapses with excitatory principal neurons, interneurons have different functions, e.g., feedback-feedforward inhibition and suppression of dendritic $\mathrm{Ca}^{2+}$ spikes (Miles et al., 1996; Larkum et al., 1999). Several classes of GABAergic interneurons in the neocortex have been identified to date (Jones, 1993; Kawaguchi and Kubota, 1993, 1996, 1997; Deuchars and Thomson, 1995; Kawaguchi, 1995; Thomson et al., 1996; Tamás et al., 1997, 1998; Reyes et al., 1998; Gupta et al., 2000), and electrophysiological recordings have demonstrated the existence of synaptic contacts between spiny layer 4 neurons and layer 4 interneurons (V. Egger, D. Feldmeyer, and B. Sakmann, unpublished results). However, their specific function in the columnar microcircuitry is still unclear. Recent evidence indicates that certain types of GABAergic interneurons are coupled via gap junctions (Galarreta and Hestrin, 1999; Gibson et al., 1999). This may support concerted activity of these neurons; however, it is still unknown which effects this may have on the flow of excitation in a cortical column.

\section{REFERENCES}

Agmon A, Connors BW (1991) Thalamocortical responses of mouse somatosensory (barrel) cortex in vitro. Neuroscience 41:365-380.

Ahmed B, Anderson JC, Douglas RJ, Martin KAC, Nelson JC (1994) Polyneuronal innervation of spiny stellate neurons in cat visual cortex. J Comp Neurol 341:39-49.

Armstrong-James M, Fox K, Das-Gupta A (1992) Flow of excitation within rat barrel cortex on striking a single vibrissa. J Neurophysiol 68:1345-1358.

Benshalom G, White EL (1986) Quantification of thalamocortical synapses with spiny stellate neurons in layer IV of mouse somatosensory cortex. J Comp Neurol 253:303-314.

Burkhalter A (1989) Intrinsic connections of rat primary visual cortex: laminar organization of axonal projections. J Comp Neurol 279:171-186.

Chiaia NL, Rhoades RW, Bennett-Clarke CA, Fish SE, Killackey HP (1991a) Thalamic processing of vibrissal information in the rat. I. Afferent input to the medial ventral posterior and posterior nuclei. J Comp Neurol 314:201-216.

Chiaia NL, Rhoades RW, Fish SE, Killackey HP (1991b) Thalamic processing of vibrissal information in the rat: II. Morphological and functional properties of medial ventral posterior nucleus and posterior nucleus neurons. J Comp Neurol 314:217-236.

Connors BW, Gutnick MJ (1990) Intrinsic firing patterns of diverse neocortical neurons. Trends Neurosci 13:99-104.

DeFelipe J, Farinas I (1992) The pyramidal neuron of the cerebral cortex: morphological and chemical characteristics of the synaptic inputs. Prog Neurobiol 39:563-607.

Deuchars J, Thomson AM (1995) Single axon fast inhibitory postsynaptic potentials elicited by a sparsely spiny interneuron in rat neocortex Neuroscience 65:935-942.

Douglas RJ, Martin KAC (1991) A functional microcircuit for cat visual cortex. J Physiol (Lond) 440:735-769.

Douglas RJ, Koch C, Mahowald M, Martin KAC, Suarez HS (1995) Recurrent excitation in neocortical circuits. Science 269:981-985.

Egger V, Feldmeyer D, Sakmann B (1999) Coincidence detection and efficacy changes in synaptic connections between spiny stellate neurons of the rat barrel cortex. Nat Neurosci 2:1098-1105.

Feldmeyer D, Silver RA, Lübke J, Sakmann B (1999a) Synaptic connections between spiny layer 4 neurones and layer $2 / 3$ pyramidal cells of rat barrel cortex. J Physiol (Lond) 518:141.P-142P.

Feldmeyer D, Egger V, Lübke J, Sakmann B (1999b) Synaptic connections between excitatory layer 4 neurones in the "barrel field" of rat somatosensory cortex. J Physiol (Lond) 521:169-190.

Galarreta M, Hestrin S (1999) A network of fast-spiking cells in the neocortex connected by electrical synapses. Nature 402:72-75.

Gibson JR, Beierlein M, Connors BW (1999) Two networks of electrically coupled inhibitory neurons in neocortex. Nature 402:75-79.

Gil Z, Connors BW, Amitai Y (1999) Efficacy of thalamocortical and intracortical synaptic connections: quanta, innervation, and reliability. Neuron 23:385-397.

Gilbert CD, Wiesel TN (1979) Morphology and intracortical projections of functionally characterised neurones in the cat visual cortex. Nature 280:120-125.

Gupta A, Wang Y, Markram H (2000) Organizing principles for a diver- sity of GABAergic interneurons and synapses in the neocortex. Science 287:273-278.

Harris RM, Woolsey TA (1981) Dendritic plasticity in mouse barrel cortex following postnatal vibrissa follicle damage. J Comp Neurol 196:357-376. Harris RM, Woolsey TA (1983) Computer-assisted analyses of barrel neuron axons and their putative synaptic contacts. J Comp Neurol 220:63-79.

Hirsch JA (1995) Synaptic integration in layer 4 of the ferret striate cortex. J Physiol (Lond) 483:183-199.

Hubel DH, Wiesel TN (1962) Receptive fields, binocular interaction and functional architecture in the cat's visual cortex. J Physiol (Lond) 160:106-154.

Jones EG (1993) GABAergic neurons and their role in cortical plasticity in primates. Cereb Cortex 3:361-372.

Juliano SL, Jacobs SE (1995) The barrel cortex of rodents (Jones EG, Diamond IT, eds) New York: Plenum.

Katz LC, Gilbert CD, Wiesel TN (1989) Local circuits and ocular dominance columns in monkey striate cortex. J Neurosci 9:1389-1399.

Kawaguchi Y (1995) Physiological subgroups of nonpyramidal cells with specific morphological characteristics in layer II/III of rat frontal cortex. J Neurosci 15:2638-2655.

Kawaguchi Y, Kubota Y (1993) Correlation of physiological subgroupings of nonpyramidal cells with parvalbumin- and calbindinD28kimmunoreactive neurons in layer $\mathrm{V}$ of rat frontal cortex. J Neurophysiol 70:387-396.

Kawaguchi Y, Kubota Y (1996) Physiological and morphological identification of somatostatin- or vasoactive intestinal polypeptide-containing cells among GABAergic cell subtypes in rat frontal cortex. J Neurosci 16:2701-2715.

Kawaguchi Y, Kubota Y (1997) GABAergic cell subtypes and their synaptic connections in rat frontal cortex. Cereb Cortex 7:476-486.

Kim U, Ebner FF (1999) Barrels and septa: separate circuits in rat barrels field cortex. J Comp Neurol 408:489-505.

Kleinfeld D, Delaney KR (1996) Distributed representation of vibrissa movement in the upper layers of somatosensory cortex revealed with voltage-sensitive dyes. J Comp Neurol 375:89-108.

Kossel A, Löwel S, Bolz J (1995) Relationships between dendritic fields and functional architecture in striate cortex of normal and visually deprived cats. J Neurosci 15:3913-3926.

Laaris N, Carlson GC, Keller A (2000) Thalamic-evoked synaptic interactions in barrel cortex revealed by optical imaging. J Neurosci 20:1529-1537.

Larkum ME, Zhu JJ, Sakmann B (1999) A new cellular mechanism for coupling inputs arriving at different cortical layers. Nature 398:338-341.

LeVay S (1973) Synaptic patterns in the visual cortex of the cat and monkey. Electron microscopy of Golgi preparations. J Comp Neurol 150:53-86.

Lund JS (1984) Spiny stellate neurons. In: The cereb cortex, Vol 1 (Jones EG, Peters A, eds), pp 255-308. New York: Plenum.

Lund JS (1988) Anatomical organization of macaque monkey striate visual cortex. Annu Rev Neurosci 11:253-288.

Martin KAC, Whitteridge D (1984) Form, function and intracortical projections of spiny neurones in the striate visual cortex of the cat. J Physiol (Lond) 353:463-504.

McCasland JS, Woolsey TA (1988) High resolution 2-deoxyglucose mapping of functional cortical columns in mouse barrel cortex. J Comp Neurol 278:555-569.

McCormick DA (1992) Neurotransmitter actions in the thalamus and cerebral cortex and their role in neuromodulation of thalamocortical activity. Prog Neurobiol 29:337-388.

McGuire BA, Hornung JP, Gilbert CD, Wiesel TN (1984) Patterns of synaptic input to layer 4 of cat striate cortex. J Neurosci 4:3021-3033.

Miles R, Toth K, Gulyas AI, Hajos N, Freund TF (1996) Differences between somatic and dendritic inhibition in the hippocampus. Neuron 16:815-823.

Mountcastle VB (1957) Modality and topographic properties of single neurons of cat's somatosensory cortex. J Neurophysiol 20:408-434.

Mountcastle VB (1997) The columnar organization of the neocortex. Brain 120:701-722.

Mountcastle VB, Powell TPS (1959) Neural mechanisms subserving cutaneous sensibility, with special reference to the role of afferent inhibition in sensory perception and discrimination. Bull Johns Hopkins Hosp 105:201-232.

Pasternak JR, Woolsey TA (1975) The number, size and distribution of neurons in lamina IV of the mouse SmI neocortex. J Comp Neurol 160:291-306.

Reyes A, Sakmann B (1999) Developmental switch in the short-term modification of unitary EPSPs evoked in layer $2 / 3$ and layer 5 pyramidal neurons of rat neocortex. J Neurosci 19:3827-3835.

Reyes A, Lujan R, Rozov A, Burnashev N, Somogyi P, Sakmann B (1998) Target-cell-specific facilitation and depression in neocortical circuits. Nat Neurosci 1:279-285.

Rockland KS (1998) Complex microstructures of sensory cortical connections. Curr Opin Neurobiol 8:545-551.

Sherman MS, Guillery RW (1996) Functional organization of thalamocortical relays. J Neurophysiol 76:1367-1395.

Simons DJ, Woolsey TA (1984) Morphology of Golgi-Cox impregnated barrel neurons in rat Sm1 cortex. J Comp Neurol 230:119-132. 
Somogyi P, Hodgson AJ (1985) Antisera to gamma-aminobutyric acid. III. Demonstration of GABA in Golgi-impregnated neurons and in conventional electron microscopic sections of cat striate cortex. J Histochem Cytochem 33:249-257.

Somogyi P, Tamás G, Lujan R, Buhl EH (1998) Salient features of synaptic organisation in the cerebral cortex. Brain Res Rev 26:113-135.

Steffen H (1976) Golgi stained barrel-neurons in the somatosensory region of the mouse cerebral cortex. Neurosci Lett 2:57-59.

Steffen H, van der Loos H (1980) Early lesions of mouse vibrissal follicles: their influence on dendrite orientation in the cortical barrel-field. Exp Brain Res 40:419-431.

Stratford KJ, Tarczy-Hornoch K, Martin KAC, Bannister NJ, Jack JJ (1996) Excitatory synaptic inputs to spiny stellate cells in cat visual cortex. Nature 382:258-261.

Tamás G, Buhl EH, Somogyi P (1997) Fast IPSPs elicited via multiple synaptic release sites by different types of GABAergic neurones in the cat visual cortex. J Physiol (Lond) 500:715-738.

Tamás G, Somogyi P, Buhl EH (1998) Differentially interconnected networks of GABAergic interneurons in the visual cortex of the cat. J Neurosci 18:4255-4270.

Tarczy-Hornoch K, Martin KAC, Stratford KJ, Jack JJB (1999) Intracortical excitation of spiny neurons in layer 4 of cat striate in vitro. Cereb Cortex 9:833-843.

Thomson AM, Bannister AP (1998) Postsynaptic pyramidal target selection by descending layer 3 pyramidal cell axons: dual intracellular record- ings and biocytin filling in slices of rat neocortex. Neuroscience $84: 669-683$

Thomson AM, West DC, Hahn J, Deuchars J (1996) Single axon IPSPs elicited in pyramidal cells by three classes of interneurones in slices of rat neocortex. J Physiol (Lond) 496:81-102.

Welker C (1976) Receptive fields of barrels in the somatosensory neocortex of the rat. J Comp Neurol 166:173-190.

White EL, Rock MP (1981) A comparison of thalamocortical and other synaptic inputs to dendrites of two non-spiny neurons in a single barrel of mouse SmI cortex. J Comp Neurol 195:265-277.

White EL, Benshalom G, Hersch SM (1984) Thalamocortical and other synapses involving nonspiny multipolar cells of mouse SmI cortex. J Comp Neurol 229:311-320.

Woolsey TA, Van der Loos H (1970) The description of a cortical field composed of discrete cytoarchitectonic units. Brain Res 17:205-242.

Woolsey TA, Dierker ML, Wann DF (1975) Mouse SmI cortex: qualitative and quantitative classification of Golgi-impregnated barrel neurons. Proc Natl Acad Sci USA 72:2165-2169.

Woolsey TA, Rovainen CM, Cox SB, Henegar MH, Liang GE, Liu D, Moskalenko YE, Sui J, Wei L (1996) Neuronal units linked to microvascular modules in cerebral cortex: response elements for imaging the brain. Cereb Cortex 6:647-660.

Wong-Riley M (1979) Changes in the visual system of monocularly sutured or enucleated cats demonstrable with cytochrome oxidase histochemistry. Brain Res 171:11-28. 